\title{
Mathematics Education and Reform in Ireland: An Outsider's Analysis of Project Maths
}

\author{
SARAH LUBIENSKI
}

\begin{abstract}
Project Maths is an ambitious reform of Irish, post-primary education. In this paper, a U.S. Fulbright scholar reports on her impressions of Project Maths, based on interviews with leaders and teachers, observations in pilot school classrooms, attendance at a teacher workshop, and analyses of materials and textbooks. The paper highlights several aspects the author found particularly impressive, including the phased, collaborative approach to Project Maths implementation, Irish mathematics teacher engagement, and the impact of the reform on some pilot school teachers. The author also raises questions about the Irish exam system, mathematics textbooks, the clarity of Project Maths' vision, and the challenge of teacher change. The paper concludes with lessons the U.S. could learn from Project Maths' example of policy development and implementation.
\end{abstract}

\section{INTRODUCTION}

I came to Ireland in Fall, 2010 to learn more about Project Maths. My 4-month visit was supported by a Fulbright fellowship and the Center for the Advancement of Science Teaching and Learning (CASTeL). During my relatively short stay, I was fortunate to have several windows into Irish mathematics education - as an instructor in Dublin City University's (DCU) School of Mathematical Sciences, as a parent of two children in Irish schools, and as a researcher who was generously granted access to several schools and offices involved with Project Maths.

I write this article as an outsider to the Irish education system. There are definite limits to what I can contribute to the discourse on Irish education as an interloper. However, I hope there might also be the benefit of fresh eyes, with my U.S. mathematics education research and experience serving as a backdrop to my analyses. 
I became intrigued with Project Maths while considering potential Fulbright opportunities in Ireland. The goals of Project Maths appeared strikingly similar to the goals of the reform movement led by the National Council of Teachers of Mathematics (NCTM) in the U.S.[11, 12, 13]. In particular, both call for more student sense making, problem solving, engagement in the classroom, and conceptual understanding to accompany procedural skill. Both NCTM and Project Maths call for more real world connections and the use of instructional technology, and both promote an increased emphasis on statistics and probability, multiple representations in algebra, and geometric reasoning. Indeed, as I scoured the Project Maths website, I was often struck by the familiarity of the quotes I encountered, such as the following:
Project Maths ... involves changes to what students learn in mathematics, how they learn it and how they will be assessed ... Much greater emphasis will be placed on student understanding of mathematical concepts, with increased use of contexts and applica- tions that will enable students to relate mathematics to everyday experience. The initiative will also focus on developing students problem-solving skills [14].

However, despite the similarity in reform rhetoric, the two reform movements were occurring in very different educational contexts. The U.S., due in part to its larger size, has a tradition of decentralized education, with decisions about curriculum and instruction left to each state. NCTM has made valiant efforts to reach teachers through publications and conferences, but actual implementation of the NCTM Standards is completely voluntary and highly uneven across states, schools, and classrooms. U.S. researchers have found that, despite professional development efforts and teachers' best intentions, changing mathematics teachers' practice is extremely difficult. Surface changes often occur, such as the use of manipulatives or technology, but there is less often substantial movement toward student reasoning and sense-making $[3,1]$.

As one who has studied the NCTM reform movement, I was impressed by the thoughtful, ambitious plan for Project Maths, scheduled to roll out to all Irish schools in 2010. With its government mandate and support, I wondered whether this reform movement, 
would, indeed, be implemented as planned, and what that implementation might look like.

\section{Data Collection and Analysis}

During my brief, 4-month stay, I was in no position to conduct a large-scale, randomized study of the implementation and impact of Project Maths. However, I did collect data about Project Maths from a variety of sources, both formal and informal. To protect informants, I am limiting the details I provide about the Project Maths leaders, teachers, and schools that participated in this study (and pseudonyms are used).

I began my research by reading dozens of documents related to Project Maths and talking informally with Irish professors of mathematics and mathematics education, who generously helped orient me to the Irish system of maths education. I also attended several relevant conference presentations, as well as a day-long workshop for teachers that was part of the Project Maths national roll-out. I conducted formal interviews (lasting 1-3 hours each) with several Project Maths leaders, including members of the Project Maths Development Team and the National Council for Curriculum and Assessment (NCCA). The interview protocol contained 18 questions, probing many different aspects of Project Maths, including its history, goals, design, teacher support, curriculum materials, criticisms, obstacles, and surprises. At the end of each interview, I asked for recommendations of pilot schools to visit.

I then conducted 1-day visits to three recommended pilot schools, spanning a broad socioeconomic spectrum. I observed mathematics lessons taught by 2-4 teachers in each school, for a total of 10 teachers. I talked informally with principals and a variety of teachers at these schools. I also conducted formal interviews with two of the observed teachers in each school, asking about their teaching backgrounds, curriculum, role in Project Maths, and implementation struggles and successes. When observing maths lessons, I utilized a classroom observation protocol that prompted me to code various aspects of the lesson (e.g., lesson design, discourse, student sense making, classroom climate $)^{1}$. This protocol served as a tool to focus my attention during observations, but I do not present statistics

\footnotetext{
${ }^{1}$ The protocol was developed by the Sense Making in Mathematics and Science Project, directed by Barbara Hug and Sarah Lubienski at the University
} 
about these aspects due to the small, non-representative nature of the sample.

Although not formally part of my research, my teaching experiences at DCU were very illuminating. I taught two modules - one for prospective teachers and one for experienced maths teachers in which we discussed Project Maths and compared texts with the Project Maths label. I am especially grateful to the teachers in my graduate course for engaging in those assignments so enthusiastically and answering my many questions about Irish maths education.

After collecting the data, I audio-recorded and transcribed all formal interviews. Although I began with initial categories of interest when I created the interview protocol, I analyzed the data primarily inductively, looking for themes that recurred and stood out, particularly as I considered Project Maths in light of mathematics education reform in the U.S.

Although rooted in data, my findings are presented more tentatively than traditional research results because of the limits of both the data I collected and my understanding as an outsider. I organize the findings into three sections. In Section 1, I comment on five aspects of Irish education that I found to be particularly impressive. In Section 2, I raise questions about a variety of issues that struck me as curious or concerning. Finally, in Section 3, I discuss a few of the many aspects of the U.S. system that I now consider more critically in light of my experiences in Ireland.

\section{Notable Highlights}

1.1. Ambitious, Collaborative Planning for Project Maths. When I first learned about Project Maths from afar, I was impressed by the coherence of the implementation plan, with its phased-in approach involving 24 pilot schools. Although things always look messier on the ground than they do on paper, I have maintained my admiration for the plan and the collaboration behind it, even after seeing Project Maths up close.

There are several groups that have played a role, including:

- National Council for Curriculum and Assessment (NCCA)

- Department of Education and Skills (DES)

of Illinois. The protocol drew from the Local Systematic Change (LSC) and the Oregon Mathematics Leadership Institute (OMLI) protocols. 
- Teacher Education Section (TES) (includes the Project Maths Development Team)

- Maths Inspectorate

- State Exams Commission (SEC)

Through my interviews with Project Maths leaders, I learned that traditionally, these various bodies have worked relatively independently, with a linear progression as follows: NCCA prepares the syllabus, DES implements, and SEC examines.

However, according to the leaders I interviewed, there has been unprecedented collaboration in the creation and implementation of Project Maths, with these groups working together toward common goals:

The collaboration with the exams committee is huge

- for the first time, there are many feedback loops ... there hasn't been an initiative like this before that is so widespread, and so complicated - its revolutionary!

- A Project Maths Leader

When we first design the [teacher] workshops, we have someone from the inspectorate, SEC, TES, and NCCA - we show them what we intend to do, ask them if they have any advice, because at the end of the day, we want to get the best product out there.

- A Project Maths Leader

The fact that $95 \%$ of workshop attendees have expressed satisfaction on post-workshop surveys indicates that this collaboration has, indeed, resulted in relevant, useful experiences for teachers. Overall, the plan for Project Maths is impressive, and the collaboration propelling Project Maths forward is indeed striking.

1.2. Implementation as Scheduled. It is one thing to create a plan for reform, but quite another to actually stick to that plan and implement it. In exploring the origins of the plan, I learned that those funding the plan wanted tangible results sooner rather than later. This pressure led to the unpopular decision to begin Project Maths implementation at both 1st and 5th years simultaneously the subject of the majority of complaints I heard from Irish teachers.

But the unpopularity of that decision should not overshadow the accomplishments of those responsible for implementing Project 
Maths. Given the political time pressures, there were only a few months between the approval of Project Maths in the Spring of 2008, and the beginning of implementation with the pilot schools in August 2008. During those few months, the Project Maths Development Team was assembled, with Regional Development Officers (RDOs) hired to support the schools (at a 1:4 ratio). Additionally, pilot schools were recruited, and a stratified sample of 24 schools was selected from the 230 schools that volunteered. The NCCA and the Project Maths Development Team quickly began drafting a new syllabus, sample lesson plans, teacher workshops, and other support materials.

Given the major overhaul of the system that Project Maths entails, the 24 schools wondered if Project Maths really would move forward as promised, after the 2-year pilot:

There was such distrust of the system. Now the 24 schools have the full picture, they have seen all 5 strands, and they have seen that all the schools nationally are starting ...they are not going to be stranded ... they're over the hump of the unknown.

- Project Maths Leader

Indeed, after the pilot phase, the national rollout began as scheduled, in August 2010. From my U.S. standpoint, the scope of work initiated and accomplished over the past 3 years is, indeed, remarkable.

1.3. Responsiveness to Feedback from Pilot Schools. During the two-year pilot, there was substantial give-and-take between Project Maths leaders and the pilot schools. Teachers were initially upset by the lack of curricular guidance available to them, and it took some time for them to understand Project Maths' intention to collaboratively develop resources with the schools during the pilot phase.

During that time, the pilot school teachers made several requests. First, the teachers asked for release time to meet with other maths teachers and their RDO, and the NCCA supported this request. Second, the pilot teachers expressed frustration at the lack of readymade student materials available to them. In response, NCCA scrambled during the Summer of 2009 and created additional resources for the teachers and their students. One Project Maths leader explained this as follows: 
It was a small little question (teachers asking for student materials), but the consequences were an entire summer of work in getting those finalized.

\section{- Project Maths Leader}

A third major concern among the pilot teachers was that they did not know what the new maths questions would look like on the Junior and Leaving Certificate exams. The leaders of Project Maths, in collaboration with the SEC, sought to address this concern:

We told them that the exams commission will create a sample paper and will trial it in the schools ...We weren't in the position in the first year to give them a paper, but we gave them sample questions.

Teachers also expressed concern about the statistics strand, arguing that it was too long and difficult, particularly for 5th and 6th year students who had not had this strand in prior years. This concern prompted two temporary adjustments, with the first being the deferment of some statistics-related material. The second was the provision of a temporary exam option:

We gave them a choice between the further end of the statistics, or a section of the geometry, and we said we will guarantee you a choice on the exam between those. So we strove to accommodate the concerns that were there by putting in a choice that originally we hadn't intended. .

$$
\text { - Project Maths Leader }
$$

Finally, many teachers indicated that they, themselves, needed help with the content they were expected to teach, especially in the area of statistics and probability. Hence, a 3-day summer course was offered for teachers in the pilot schools, and DVDs of this course were made for all teachers in Ireland. Additionally, evening workshops focusing on maths content are now available during the school year for all Irish teachers, to supplement the more pedagogical-focused workshops offered during the school day.

Overall, the pilot school teachers I talked with were pleased at the level of support they received from their RDO and other Project Maths leaders (although pilot teachers told me that experiences varied across the schools, depending upon the assigned RDO). According to an NCCA survey administered at the end of the first pilot year, the majority of pilot schools reported being happy they were 
involved. Still, this same survey indicated that Project Maths placed extra demands on teachers time. Indeed, the prevailing sentiment of the pilot teachers I interviewed was that involvement as a pilot school was extra work but worth it:

I really think the students are getting a better feel for maths, and even though we had an awful lot of work to do the first year, we had a great experience from it.

- Nancy, pilot school teacher

What it's trying to do is beyond reproach - I think it's the only way to go if we're going to get students to be math literate and be able to apply maths. But that's not to say that it hasn't had problems... that it hasn't placed a huge workload on teachers.

— Ned, pilot school teacher

1.4. Teacher Professionalism. When I talked with teachers in Ireland, I was often struck by their deep concern for students, their interest in improving instruction, and their involvement in the profession. The quotes from Nancy and Ned above nicely illustrate this commitment to improved mathematics education. On a broader scale, I learned with interest about the active Irish Mathematics Teacher Association, including some heated debates about Project Maths (e.g., particularly at the Dublin branch meetings). Although one might prefer a serene picture of unanimous agreement among the mathematics teachers of Ireland, it is impressive that Irish teachers care enough about their profession to argue about it, without allowing these debates to derail progress toward common goals of improving mathematics instruction.

I am also impressed by the fact that the vast majority of teachers are attending the Project Maths workshops nationally. At the time of my visit, 3 of the 10 national, day-long workshops had occurred, with over $80 \%$ of Irish Maths teachers attending (according to figures given to me by Project Maths leaders). Additionally, as of Fall, 2010, at least 2000 teachers (1/3 of all mathematics teachers in Ireland) had attended an evening Project Maths workshop to learn more mathematics content or instructional technology. Participation in these evening workshops is not required or compensated in any way — teachers simply want to learn and improve their practice. 
In the U.S., there seems less of a tradition of teacher involvement in local maths teacher organizations, and more of a tradition of mandating and paying teachers to attend professional development. Given the differences in incentives and participation, I was indeed impressed by the level of interest and professionalism I found among Irish teachers.

1.5. Pilot School Teacher Change. At the beginning of the study, I had wondered if implementing Project Maths in the volunteer pilot schools was somewhat like preaching to the choir, perhaps involving only those teachers who supported and already implemented instruction aligned with Project Maths. However, during interviews, teachers in each of the three schools talked about substantive changes they made in their classrooms. For example, one teacher, Elizabeth, said that her instruction had drastically changed:

I'm getting them to think and do problem solving. It used to be rote learning. I'm really excited about the geometry. It used to be taught in 3rd year right before the exam. It was "Here are your theorems, learn it off." ...I'm taking a back seat more now. I'm doing more work at home, but less talking in class.

Additionally, Ned, told me about his new instructional approaches, particularly in the area of statistics:

...I've been surprised at the innovation in some of the approaches of teaching topics. It's been a real eye-opener ... What's really encouraging is that students are getting experience with the "why" of statistics ... and actually applying that to real situations for example in the "Census of Schools" activity, they get data from other schools... Students are actually making decisions for themselves - if comparing 2 datasets, do they use mean, median, or mode? Before it was just "know how to calculate each one."

Another teacher, Mike, told me that he was initially against Project Maths and felt that it would be "dumbing down" the curriculum. However, he was not against being a pilot school:

Whether we were a pilot school or not, we were going to have to teach the new syllabus - we may as 
well be in there at the start - where we can have

some input on the changes.

After two years of piloting Project Maths, Mike still had concerns about the elimination or treatment of some topics (e.g., vectors). However, he also saw important benefits to the Project Maths approach:

I feel less reserved about Project Maths now, because the syllabus makes a big effort to be more tangible and practical, so students can see how maths fits in with the real world. Some of the materials ... are good to motivate students, easing them in to topics, so I do like that approach. And the new Project Maths] exams are at times quite challenging as well, because students in the past never had to move from a context to actually formulating some mathematical problem that they then had to solve themselves.

Having no "pre-Project-Maths" data on these teachers, I am in no position to judge the extent to which changes have actually occurred in their classrooms, and I cannot say how typical these teachers are. Still, given the persistent difficulties of changing teachers deeply held beliefs about mathematics teaching, it is, indeed, impressive that fundamental changes in beliefs and practices were described by three of the six pilot school teachers I interviewed. The Project Maths lesson plans, workshops, and RDOs were regularly mentioned as influential.

\section{ISSUES FOR IRELAND TO CONSIDER}

One of the things that repeatedly struck me about Ireland was its relatively small size - e.g., RDOs from around the country could come together for face-to-face meetings. This close proximity obviously offers benefits in terms of greater communication and coherence. On the flip side, there are fewer human and financial resources from which to draw upon in a smaller country. This issue of country size was important for me to consider as I made sense of the Irish system. At times, I was amazed at all that the Project Maths team was able to accomplish, given the limited staff and funds. At other times, I wondered if my thoughts about what should be or could be occurring in Ireland were too rooted in my experiences in a much larger system. It is against this backdrop that I move to a discussion 
of questions I have about Irish education in general, and the implementation of Project Maths, in particular. I begin with relatively extended discussions of the Irish exam system and then textbooks, followed by brief observations about Project Maths' vision and the challenges of teacher change.

2.1. The Leaving Certificate Exam. The most striking feature of the Irish system to me, coming from the U.S., was the pervasive emphasis placed on the Leaving Certificate exam. I was struck by this emphasis in the lessons I observed, in my interviews with teachers, and in the textbooks I examined. As one small example, I noticed that some Irish textbooks routinely highlight specific questions that appeared on prior exams, along with the number of marks each question was worth.

U.S. students usually take a college entrance exam - either the Scholastic Aptitude Test (SAT) or the American College Test (ACT), or both if students wish. Although some students attend the equivalent of "grinds" for a short time to prepare for the SAT or ACT, there is generally not such a "teach to the college test" focus in U.S. secondary schools. There are annual tests given to elementary and secondary students by governing authorities, and teachers are feeling increasing pressure to teach to these tests. However, in most states these tests are high-stakes for teachers and schools - not for the students - thereby weakening public support for focusing on these tests.

Still, the SAT and ACT are high-stakes exams, and while in Ireland I began to wonder why U.S. teachers rarely teach to the college entrance tests. I believe that one major reason is that the exam content in the U.S. is less predictable. That is, the exams are copyrighted, and the questions contained on each test are considered just a small sample of all possible questions, with no pattern in what might occur from one form to the next. The fact that the SAT began as an effort to measure "IQ", traditionally perceived as "raw, mental ability" as opposed to learned content, likely also shapes people's perceptions of these tests today.

A second, related reason for less teaching to the test might be that American students can repeat the exam every few months (for a fee) if they do not like the score they earned the first time. Third, the fact that independent, non-governmental testing organisations create and administer the tests might also create more distance between 
the tests and the schools. Finally, students' SAT or ACT scores are considered along with students' grades, application essays, extracurricular activities, and teachers' letters of recommendation as colleges make selection and funding decisions.

Despite my concerns about a "teach to the test" emphasis and the consequent promotion of external rather than internal motivation for learning, high-stakes exams do have some benefits. As Conway and Sloane write,

One of the advantages of an exam tradition in any educational culture is the very fact that it is reflected in some degree of shared understanding about what knowledge is valued...how students go about the actual exam (typically, a sit-down paper-and-pencil mode of assessment), and most importantly there is typically a very significant degree of credibility attached to the results in terms of both their validity and fairness. [5, pp. 234-5]

In weighing the benefits and drawbacks of the "exam tradition" in Ireland, I discerned several themes in my notes and interviews, including the role of the teacher, impact on classroom instruction, the purpose of exams, the role of exams in education reform, and the credibility attached to the exams.

2.1.1. Teacher as exam coach. Irish teachers seem to play the role of "exam coach" with students, where its "us against the exam." Even though the Junior or Leaving Cert was months - or years - away, I noticed several Project Maths pilot teachers routinely giving their students hints about how to score points with exam graders - e.g., "Don't color in the bars [on the bar chart]. It won't count-it's a waste of time."

On the one hand, this nicely places the teacher and student on the same team, more so than is the case in the U.S. Indeed, many teachers seemed to view their role as getting students to succeed on the exam, and I was touched by the concern that teachers expressed about their students. Several teachers told me about the tradition in their school to wait outside the exam room door (on the teachers' day off), so they could talk to their exiting students and find out, "Did I prepare them on the right stuff?" Project Maths pilot teachers faced additional anxiety about the new questions on the maths exam. One such teacher, Mike, told me: 
I couldn't sleep the night before the Leaving Cert it's the first time I ever had that kind of worry in me.

Despite the benefits of this "us against the exam" approach to learning, one potential drawback is that this tends to place mathematical authority with the exam that looms in the future instead of with the teacher, perhaps providing less motivation for Irish secondary students to engage in daily classroom activities not directly linked to exam preparation. As I was teaching undergraduates at DCU, I wondered if some of the exam-focused mindset also impacts Irish students' approaches to learning in college. I was surprised at the number of my students who seemed content with a $40 \%$ average (and I was surprised that $40 \%$ instead of $60 \%$ was the passing cutoff). I had always been annoyed with my anxious, grade-conscious students in the U.S., who flood my email inbox with questions about assignments and are unhappy with scores below $95 \%$. But I began to feel a little nostalgia for my neurotic students back home, who view me - as opposed to a distant exam grader - as the final authority to be feared.

2.1.2. Exams constraining instruction. In my observations and interviews, I noticed four ways in which exams might constrain Irish mathematics instruction:

A. Gaming the system.

While some Project Maths pilot teachers spoke specifically about resisting the urge to teach strictly to the test, other teachers had a beat the exam mindset when making curricular decisions:

In the old system with ordinary math, with geometry constructions and theorems, there would be a question, but students would avoid it. So over the years I didn't do it. So it was a whole area that I had to get back into [now with Project Maths]. There were 6 questions to be done out of 8 . Learning the formal proofs was something they didn't like, so then you tended to say, "Why invest time in a question that they won't end up doing?"

- Eliza, Project Maths pilot school teacher

Project Maths is now causing Eliza to return to teaching theorems, given that the new exam will not allow students to avoid such 
questions. However, this "beat the exam" mindset can also affect instruction in other ways.

B. Time pressures.

Shortage of time can inhibit teachers' willingness to involve students in mathematical problem solving and sense-making, particularly as the Leaving Cert draws nearer and teachers feel increasing pressure to cover the curriculum. Indeed, an NCCA survey administered to pilot schools after their first year of Project Maths revealed that over $80 \%$ of schools reported greater student engagement with mathematics among 1st year students, while this percentage was less than $60 \%$ for 5 th year classrooms. As one leader explained, "The idea you have to cover the course is a big thing here. It's harder to get teachers to focus on what the students are learning, or understanding."

As a side note, coming from the U.S. where daily maths classes of 45-50 minutes are common, I was surprised at how short the class periods were that I observed in the pilot schools (typically 35-40 minutes). The difference in time available for maths appears to be due, at least in part, to the inclusion of religious education and Irish language classes - two subjects not required in U.S. public schools.

C. Form over substance?

A third issue arose as I observed the Project Maths day-long workshop and pilot school classrooms. I noticed that some teachers placed great emphasis on the format of student responses, with the focus on writing answers in a way that would maximize marks awarded on the Junior and Leaving Cert exams. For example, at the Project Maths workshop, the leader introduced white boards as one tool for problem solving, allowing students to work on ideas and easily erase and start again as needed. While some teachers remarked that they liked this non-threatening way for students to approach difficult problems, another teacher (with nods of support from several colleagues) said, "I don't want my kids to rub out mistakes, because examiners want to see their work." I also noticed the "form over substance" emphasis when the teacher (mentioned above) told the third-year student not to "waste time" coloring in the bars of his chart. In truth, the student's colored chart showed the pattern of interest better than the non-colored chart, yet the teacher did not consider this. Hence, I began to wonder how often this emphasis on "proper exam form" interferes with substantive learning goals. 
D. Distinction between instruction and assessment?

When I made my first public presentation in Ireland, I flippantly stated that "real-world problems" are important for students to encounter in mathematics classrooms, but they do not always make the best exam problems. I received several surprised looks and was later told, "We don't teach problems that aren't on the exam."

However, I stand by my statement that some problems are better for instruction than for assessment. Some mathematics problems can help students understand the exploratory nature of mathematics, including the beauty of mathematical patterns. For example, secondary school students can enjoy being exposed to unsolved mathematics problems, or figuring out how many squares or rectangles are on a chessboard. Other problems help students understand a concept more deeply, such as the locker problem, which illuminates why a number has an odd number of factors if and only if it is a square number $^{2}$. And other problems can help students grapple with messy, real-world applications of mathematics, where there are many constraints to be considered and there is rarely a single right answer. However, these problems are not necessarily good exam questions.

Exam questions are designed to assess particular content and processes, and exams are designed to sort students along a continuum for college admission purposes. Exam questions must be succinctly worded, unambiguous, solvable in a short time period and generally should have a correct answer that is easy to mark. Hence, despite the many benefits of having content alignment between instruction and assessment, I propose that there should not be too tight a coupling between the maths problems used in instruction and on exams. That is, teachers should be free to use messy, engaging mathematics problems that can teach students interesting things about mathematics, regardless of whether those particular problems will show up on the Leaving Cert.

2.1.3. What is the purpose of the exams? Of course, the above discussion raises the question of what, exactly, are the purposes of the exams, and this is something I began to wonder about as I heard the following remarks from teachers:

\footnotetext{
$2_{\text {http: }} / /$ connectedmath.msu.edu/CD/Grade6/Locker/index.html (Accessed 1-4-2011)
} 
I can't for the life of me figure out why there's so much guesswork as to what's going to be on the exams [with Project Maths]. The results aren't going to be as good.

It is unfair on students. The very first day the students start the Leaving Cert, they should know the structure of the exam, and what types of questions they will need to answer.

It's not fair to not allow them to use a calculator on a test if they have been using it as a resource in school (Regarding a university placement exam given at orientation)

Students would freak out if the questions were out of order.

Indeed, I was surprised at the predictability of the Irish exams, and the common expectation that students should be able to predict what questions will be asked and in what order. I began to wonder what the purposes of the Leaving Cert are - to reward students' memorization skills? To assess student understanding of mathematical ideas? To assess students' problem solving and reasoning skills? To help evaluate and/or improve teachers or textbooks or schools? To predict students' future success in university programs? To predict student success in future careers? I began to wonder whether the predictability of the Leaving Cert exam is helping or hindering those purposes.

Overall, I suspect it is a good thing that Project Maths is striving to make the maths exam questions less predictable with fewer options for students to omit parts of course content. That said, I became concerned at the Project Maths workshop for teachers, where substantial time was spent on a clinometer problem that was difficult for many students who took the Project Maths trial paper. The discussion of that problem prompted some teachers to ask insightfully whether this was becoming just another form of "teach to the test," where teachers are now being coached how to prepare their students for new, but still predictable problems. This issue of predictability and the purposes of the exam is something for Project Maths leaders and others across Ireland to continue to grapple with. 
2.1.4. Exam as both change lever and barrier. For Project Maths and likely other Irish education reforms, the exam system presents both a barrier to change and a lever of change:

Teachers in schools where students have always done well on the exams are harder to convince.

Teachers absolutely wanted to hold on to the old style ... They want things they can teach kids in advance. Teachers need to trust that IF they develop the skills of the students, then they will be able to figure out a novel question ... Students and teachers had a predictable exam, and teachers could train their students to practice for the exams. We removed that predictability ...

- Project Maths leaders

Indeed, teachers who view their role as preparing students for exams, and who have had success in the past, are understandably reluctant to change their instruction. Additionally, as noted previously, exams can add time pressures for teachers, making them less inclined to try new approaches, particularly those that promote deeper instead of broader content coverage.

But the fact that the Project Maths leaders have worked closely with the SEC to revise the exams has provided a necessary lever of change. The first sample exam containing Project Maths questions made the reformers' intentions "real" to the pilot school teachers:

Teachers could see student answers, responses on the problems, and the teachers could see the big picture 'Oh, we see what you want us to do.' This document was powerful.

- A Project Maths leader

When talking with teachers, I routinely asked if they thought that many teachers would simply ignore Project Maths and hope that it would go away (a fairly common reaction to school reform in the U.S.). However, I was consistently told "No," that teachers would need to get on board with Project Maths because of the changing exams. Indeed, the vast majority of Irish teachers have flocked to workshops in order to receive materials and instruction that will help them align their instruction with Project Maths. 
Another reform that occurred while I was in Ireland was the announcement that the Irish Universities Association would give 25 bonus points for students who passed the higher-level maths Leaving Cert exam ${ }^{3}$. This, again, illustrates how the Irish exam system has a powerful lever of change built in, allowing leaders to efficiently address difficult problems, such as a shortage of students pursuing higher-level maths. There is no equivalent policy lever in the U.S.

2.1.5. Credibility of the exams. The final question I raise about the exams system stems from teachers' responses to my questions about the probable impact of Project Maths on students' Leaving Cert scores. I received several responses suggesting that the SEC will "just make the results come out," or in other words, that the exam results will show whatever the DES and NCCA want them to show. Hence, I began to wonder what checks and balances there are in the Irish exam system, how much trust the Irish people have in the exam scores, and whether bridging studies would be used to compare students' results on the old and new maths exams. And I was, again, struck by the issue of country size, as I considered the vast amount of specialized testing expertise necessary to create, validate, administer, and analyze results of national exams, not to mention the additional burden placed on the exam system by reforms, such as Project Maths. I did not have the opportunity to speak with those at the SEC during my short stay in Ireland, but I was pleased to learn that the NCCA has funded a group (from the United Kingdom) to conduct research on Project Maths' impact on student learning. I applaud this external involvement in the evaluation of Project Maths, and I hope this group will work closely with the SEC and make full use of all relevant exam data.

Overall, as I talked with people from various walks of life in Ireland, I was struck by their love/hate relationship with the exam system. On the one hand, the exams are the target of much complaint, occasional distrust, and are a source of stress for teachers and students. On the other hand, people were quick to defend the system as the fairest way to allocate university slots (despite the fact that some students can afford grinds more than others). Given the importance of the exams, the SEC has tremendous responsibility and merits ample support as it copes with the changing demands brought on by the Project Maths reforms.

\footnotetext{
${ }^{3}$ Irish Independent, October 12, 2010.
} 
2.2. Textbooks. Despite the lack of any official government mandate for the NCTM reforms in the U.S., in the early 1990s, the federal government's National Science Foundation chose to invest millions of dollars in the development of textbooks aligned with the NCTM Standards. The NSF-funded author teams included scholars with expertise in the teaching and learning of the various relevant mathematical areas (e.g., algebra, geometry, statistics, etc.). Each author team partnered with mathematicians and school teachers as they developed, piloted, assessed and revised their text for publication. The process generally took 4-5 years. The NSF made this major investment because of past lessons learned about the critical importance of textbooks in maths instruction and reform. These lessons are not specific to the U.S., as Conway and Sloane note:

The message from the TIMSS textbook study is loud and clear: there is a mismatch in many countries between reform goals in mathematics and the actual mathematics embodied in textbooks Looney (2003), in research with teachers working in the support services for post-primary, found that they believed the textbook was more influential than the curriculum in making decisions about classroom teaching [5, p.31].

Given textbooks' function as mediators between curricular intention and implementation, a reform of post-primary mathematics toward a more problemsolving orientation will, it could be argued, necessitate a radical overhaul of mathematics textbooks. [5, p. 166]

Given the importance of textbooks, there are two issues that I wish to highlight - one specific to Project Maths, and the other more general.

2.2.1. Textbooks and Project Maths. First, the issue of textbooks in Ireland seems politically sensitive, with Project Maths leaders seemingly afraid to say anything positive or negative about any particular book. They appear to be circumventing textbooks as opposed to leveraging them, as illustrated by these quotes:

I deliberately have not seen any of the textbooks.

I haven't seen any [texts] so I don't know what's out there - and the best thing to do is not look 
at them, so I can hand on heart say 'I havent seen any'.

The teacher needs to be autonomous and say 'Oh, I realize it's all active learning' - they need to be able to develop this [curriculum materials] themselves.

- Project Maths leaders

Many of the pilot school teachers clearly struggled with the lack of a textbook, both because of the time it took for them to plan lessons, as well as students' difficulty with keeping mountains of handouts organized. However, now that Project Maths is in the national rollout stage, there are several "Project Maths" textbooks emerging on the market, and schools are beginning to adopt these. I looked carefully at two of these texts and was struck by their differences, with one text presenting traditional boxed formulas and examples for students to follow and the other text structuring a sequence of investigations through which students derive the formulas. Clearly, not all texts claiming the "Project Maths" label will help teachers implement the type of instruction that Project Maths envisions. Instead of circumventing textbooks, Project Maths leaders might need to help teachers develop tools to critically analyze these various texts, so that teachers will select texts that help instead of hinder the goals of Project Maths. Professional development activities that ask teachers to compare texts with a focus on the treatment of specific topics, such as the development of the distance formula, can promote valuable analyses and conversation among teachers.

2.2.2. Textbook development in Ireland. I was surprised to learn that many Irish maths textbooks are authored by mathematics teachers (often while they are teaching full time), with little or no substantive input from mathematics education scholars or mathematicians. Clearly, teachers have much practical teaching expertise that should inform textbook development. But I want to offer one example of how additional expertise is needed, and this comes, not from Project Maths, but from the 5th class textbook my daughter used while in Ireland.

There has been substantial research on students' learning of geometry, including work demonstrating Van Hiele's theory of how students progress from viewing shapes in informal to more formal 
ways [6]. The classic example is that young children tend to think that a square is a square because it "looks like a square." If you turn the square 45 degrees, most youngsters will say it is no longer a square (it's now a "diamond"). Hence, elementary mathematics education experts know the importance of designing tasks that prompt students to pay attention to the specific properties of shapes and move beyond erroneous assumptions about shape orientation.

Given that backdrop, I was dismayed when my daughter repeatedly came home with assigned problems in which the textbook showed shapes in a traditional "upright" orientation - with a horizontal base - accompanied by the question "How many horizontal (or vertical) lines are in a pentagon (or octagon, hexagon, etc.)?" My daughter soon learned that to get the textbook's expected answer, one needed to assume that the orientation shown in the picture was the only acceptable orientation for those shapes (i.e., there is 1 horizontal line in a pentagon, 2 in a hexagon and octagon, etc.).

Obviously, mistakes and missed opportunities can be found in textbooks all over the world, and these are just a few examples from one book. However, in talking with teachers, including some who were textbook authors, I grew concerned about several issues. First, it is unclear to me how a teacher can focus on both teaching full time and authoring a textbook, particularly one that needs to be completed within a year (the timetable for some of the new "Project Maths textbooks"). Second, I think both mathematics education scholars and mathematicians have a greater role to play in at least reviewing books, if not actually co-authoring them. Mathematics education scholars would notice the blatant disregard for what is known about geometry learning in the above examples. Mathematicians would likely notice other issues, such as the messages that texts convey about proof. I noticed, for example, that one of the new Project Maths texts uses what might be considered "proof by 2 examples" - e.g., concluding that the midpoint formula holds after working for two cases. Despite my enthusiastic support for the inquiry spirit of this textbook, I think mathematicians might rightly raise cautions about students learning to generalize in this way.

2.3. Project Maths Vision? The more I delved into Project Maths, the less sure I became about what, exactly, its instructional vision is. In the U.S. reform movement, the push has been toward problem solving as the primary means of learning mathematics $[12,13]$. That 
is, students are given a problem (or a carefully designed sequence of questions), and through the process of solving and discussing, they gain understanding of intended mathematical ideas. The Project Maths teaching and learning plans I examined were consistent with this approach. However, after interviews with key Project Maths players, I became less sure about the role of problem solving and discovery learning in Project Maths.

We're not quite into the Realistic Maths Education approach which is, 'Here's a problem, let's puzzle our way through that.' We want more problem solving, we want to develop those skills, but we can't go whole hog, we're taking a mix and a match. We're putting in some basic maths learning but then seeing it applied through contexts, through problem solving.

Project Maths leader

Project Maths is more about investigational work ... it's directed discovery learning - you give them a path to follow, and if they follow that path, they should get to the conclusion itself. And you're there to maybe jockey them along a little bit. But that's only 5-10 minutes of the class. The rest of it [the lesson] is back down to what's been working for thousands of years - so it's a bit of both.

Project Maths textbook author

There can be benefits to having room for interpretation of a reform vision, as it allows broader buy-in to that vision. But the downside is that teachers can read what they want to read in reform documents, and too quickly assume that they teach as reformers intend. I observed this phenomenon to varying degrees during some of my pilot classroom visits. Consequently, it might be helpful for Project Maths leaders to discuss distinctions among teaching "about," "for," and "through" problem solving, both with each other and with teachers [7]. More clarity and specificity may help spur Project Maths teachers toward deeper dialogue and more meaningful change in the classroom.

In addition to clarifying the role of problem solving, Project Maths leaders may need to grapple with the question, "What is a problem"? I noticed a tendency to equate "teaching through problem solving" with "Realistic Mathematics," which assumes that problems are set 
in real world situations. However, there are many good mathematics problems that have no real world context. "Realistic mathematics" is not the only form of problem-centered instruction. Some NSFfunded curricula in the U.S. may offer a slightly different interpretation of "teaching through problem solving," including Core Plus, Math Connections, and Connected Mathematics Project ${ }^{4}$.

2.4. The Challenge of Teacher Change. Research on U.S. mathematics education reform suggests that effective maths professional development involves intense, sustained contact with teachers and focuses on both the textbooks that teachers use and students' thinking about mathematics [2, 4]. Pilot schools have enjoyed ongoing contact with their RDOs, including regular school visits. The pilot school teachers I talked with agreed that this level of support is necessary, and some wondered how teachers in other schools will cope with only a few 1-day workshops each year:

I worry an awful lot about the other schools. All they're getting is a few workshops. They don't have somebody coming into the school helping them like we do.

- Elizabeth, pilot school teacher

In a letter written in April, 2009, the Dublin branch of the IMTA also expressed their concerns about the scope of change and the need for teacher support:

The existing Probability and Statistics option is answered by only 2-3\% of students... This means the existing pool of Mathematics teachers to Higher Level will not just have to be trained in new methodologies but will need further Mathematics education. The extent of curricular change is huge as confirmed by the experience of the teachers in the pilot schools.

Professional development is time-consuming and expensive. With Project Maths, teachers are being asked to teach material they never learned in ways that require more - not less - mathematical confidence. Additionally, almost half of those who teach post-primary maths in Ireland have no mathematics teaching credential [15]. This

\footnotetext{
${ }^{4}$ More information about these curricula can be found at http://www.wmich.edu/cpmp, http://www.its-about-time.com/math/index.html, and http://connectedmath.msu.edu. (All accessed 1-4-2011).
} 
situation raises several questions, many of which would take additional resources to address. Will the non-pilot teachers receive enough support for Project Maths implementation? Should mathematics content be at least as important as pedagogy in the Project Maths workshops? Is there a way to offer additional content or content/pedagogy hybrid workshops for teachers during school days? Should graduate courses play a larger role?

Despite these questions, I am impressed by recent reports offering recommendations for the improvement of Irish teacher education. For example, the Project Maths Implementation Support Group (2010) argued for the creation of university mathematics content/pedagogy graduate courses to support the implementation of Project Maths, as well as for requiring teachers to regularly participate in professional development as part of their ongoing registration with the Teaching Council. These directions appear promising.

\section{Issues FOR THE US TO CONSIDER}

My experiences in Ireland prompted me to regularly ask why we do things the way we do in the U.S.. Given that this article is directed toward an Irish audience, I will not dwell on all of my thoughts pertaining to the U.S., but will offer a few as points of contrast with the Irish system.

3.1. Scholarly discourse leading to policy. The U.S. has many warring interest groups that issue reports and counter-reports about education policy. There is a tendency for these groups to demonize opponents, obscure facts, and use "crisis rhetoric" as a means of persuasion. It was a breath of fresh air to read Irish mathematics education research reports, which tended to use both previous reports and the latest evidence to build toward arguments for more effective policies. Similarly, it was refreshing to have my questions about public relations campaigns for Project Maths met with confusion (due to the absence of such campaigns) and to hear remarks from Project Maths leaders, such as, "Positive and negative reactions have contributed to very useful debate." Although I'm sure there are ugly politics in Irish education just as anywhere else, my experiences there have made me more concerned about the state of education discourse in the United States.

As just one example that contrasts with what I typically see in the U.S., I could clearly identify a tight, 3-year progression of research 
and discussion leading up to Project Maths, as I read through the following four reports:

- Inside Classrooms: The Teaching and Learning of Mathematics in Social Context [8] concluded that much of Irish mathematics instruction centers around teacher lecture, memorization of procedures, and drill.

- International Trends in Post Primary Maths Education: Perspectives on Learning Teaching and Assessment [5] discussed a variety of international initiatives, highlighting the trend toward more problem-centered mathematics instruction.

- A Discussion Paper: Review of Mathematics in Post Primary Education [9] was a companion to the International Trends report and outlined the current state of mathematics education in Ireland as a way of fostering discussion. This was distributed to all schools and colleges as the start of a consultation process that involved an online survey and focus group meetings with parents, the IMTA, etc.

- Review of Mathematics in Post-Primary Education: Report of the Consultation [10] summarized the results of the discussion process.

Unlike many reports in the United States, these Irish reports presented evidence and raised questions to spur discussion, progressively building toward a collective understanding. Even more impressive is the fact that the reports culminated in the creation and implementation of a major national reform.

\subsection{Thoughtful approaches to policy implementation.}

Project Maths teachers and leaders impressed me with their wise, long-term perspectives on reform, often expressed in response to my queries about how they will know if Project Maths "is working:"

I think it's far too soon to say that it's working. From my own experience, I'm only teaching Project Maths full time this year, and that's to students who have no history learning in this way. So in 2 years time, I would expect to see differences - or in 3 years time, when things get more smooth.

Ned, Project Maths pilot teacher

The proof in the pudding will be after students have been through the entire program — students 
won't have emerged from the system until 2017 we said at the start that it will be 7-10 years before the whole system is in place. But the benefit of staggering in like this is that it gives time for the system to settle in - it would have been a nightmare to shift everything over all at once.

Project Maths leader

Project Maths' staggered implementation, beginning with 24 volunteer pilot schools and introducing 1-2 mathematics strands per year, seems a smart approach, allowing 2 years in which to work through major issues before scaling up to the rest of the country. Similarly, I was impressed at the thoughtful way in which a maths bonus points reform was introduced, with an announcement made in 2010 that the policy would begin in 2012 on a four-year trial basis ${ }^{5}$.

In the U.S., unreasonable expectations of quick results have too often led to the rapid abandonment of policies, along with pendulum swings in education rhetoric and reform. This has created the popular "wait for it to go away" response among educators. Indeed, reform implementation takes time, and seeing the effects of that implementation takes even longer. The U.S. could learn much from these Irish examples of thoughtful policy introduction.

3.3. Exams. My time in Ireland gave me an appreciation for some aspects of the U.S.' relatively low-stakes exam system, yet, I did begin to grapple with several questions. First, I began to wonder why the U.S. allows private testing groups - as opposed to a government body - to determine the content of college entrance exams. These exams could provide a focal point for public discourse, as well as a key policy lever that is missing in the U.S. (although I do fear that this lever could be over-used if subject to the whims of U.S. policy makers).

Second, I began to question the timing of U.S. exams, which generally occur before students' final year of high school, making "senioritis" (students having little regard for their senior year) a problem among U.S. students. In fact, the college testing, application and selection process occurs on a completely different timeline, often spanning two or more years in the U.S., as opposed to only the summer months following secondary school in Ireland (however,

\footnotetext{
${ }^{5}$ Donnelly, K. (October 12, 2010). 25-point bonus for passing honours maths, Irish Independent.
} 
there is no "transition year" in the U.S.). I am still considering the trade-offs of each approach.

Finally, as I talked with Irish teachers who expressed great concern for their students' performance and future opportunities, I began to wonder about the current situation in the U.S., which tends to place teachers in a very difficult position of teaching to state-level tests that are high-stakes for themselves, but low-stakes for their students. This situation is intensifying amid proposals linking U.S. teachers' salary to their students' performance on such tests. Watching teachers and students who are so clearly on the "same team" in Ireland has made me think more critically about the U.S. approach to high-stakes testing.

\section{PARTING WORDS}

Overall, I am grateful to the Project Maths leaders and teachers in Ireland who welcomed me warmly and shared their thoughts with me openly. I am also grateful to DCU and CASTeL for hosting my visit. I was consistently impressed by the professionalism and collegiality of Ireland's mathematics educators, at the elementary, secondary and university levels. I look forward to seeing the fruits of the Project Maths team's labours as I continue to watch with keen interest from the other side of the pond.

\section{ACKNOWLEGEMENTS}

Support for this project was generously provided by the following parties: J. William Fulbright Foreign Scholarship Board, U.S. Department of State; Center for the Advancement of Science Teaching and Learning (CASTeL); Faculty of Science and Health, DCU; Office of the Vice-President for Research, DCU; College of Education, University of Illinois, Urbana-Champaign. I am also grateful to Paul Conway, Sean Delaney, Christopher Lubienski, Brien Nolan, and Maurice O'Reilly for their helpful comments on an earlier version of this manuscript, and to Anthony O'Farrell for facilitating the publication of this article.

\section{REFERENCES}

[1] Ball, D.L.: Reflections and deflections of policy: The case of Carol Turner.Educational Evaluation and Policy Analysis 12(3) (1990) 263-275. 
[2] Carpenter, T.P., et al.: Using knowledge of children's mathematics thinking in classroom teaching: An experimental study. American Educational Research Journal, 26 (1989) 499-531.

[3] Cohen, D.K.: A Revolution in One Classroom: The Case of Mrs. Oublier. Educational Evaluation and Policy Analysis, 12(3) (1990) 311-329.

[4] Cohen, D. K. and Hill, H. C.: Learning policy: When state education reform works. Yale University Press. New Haven, CT. 2001.

[5] Conway, P. and Sloane, F: International Trends in Post Primary Maths Education: Perspectives on Learning, Teaching and Assessment. NCCA. Dublin. 2005.

[6] Crowley, M.C.: The van Hiele model of the development of geometric thought. In M. Lindquist \& A. Shulte, (Eds.), Learning and Teaching Geometry K-12 (pp. 1-16). NCTM. Reston, VA. 1987.

[7] Lubienski, S.T: Perspectives on problem-centered mathematics teaching. Mathematics Teaching in the Middle School, 5 (4) (1999) 250-255.

[8] Lyons, M., Lynch, K., Close, S., Sheerin, E. and Boland, P: Inside Classrooms: The Teaching and Learning of Mathematics in Social Context. IPA. Dublin. 2003.

[9] NCCA: A Discussion Paper: Review of Mathematics in Post Primary Education. NCCA, Dublin. 2005.

[10] NCCA: Review of Mathematics in Post-Primary Education: Report of the Consultation. NCCA, Dublin. 2006.

[11] National Council of Teachers of Mathematics: Curriculum and evaluation standards for school mathematics. MCTM. Reston, VA. 1989.

[12] National Council of Teachers of Mathematics: Professional standards for teaching mathematics. NCTM. Reston, VA. 1991.

[13] National Council of Teachers of Mathematics: Principles and standards for school mathematics. Reston, VA. 2000.

[14] Project maths Develoment Team: Overview of Project Maths. http://www.projectmaths.ie/overview (Accessed 1-4-2011)

[15] Ní Ríordáin, M. \& Hannigan, A.: Out-of-field teaching in post-primary mathematics education: An analysis of the Irish context. NCE-MSTL, University of Limerick. 2010.

Sarah Lubienski

University of Illinois,

Urbana-Champaign,

IL 61820, USA

stl@illinois.edu

Sarah Theule Lubienski is a professor of mathematics education in the Department of Curriculum and Instruction at the University of Illinois, Urbana-Champaign, USA. She studies mathematics instruction, reform and equity. Her research has included analyses of large-scale data on U.S. 
mathematics achievement and instruction (NAEP and ECLS-K), as well as classroom-based studies.

Received 28-2-2011, and in revised form 14-3-2011. 


\section{Message from the EMS}

You may be interested to know that the European Mathematical Society has created a multi-lingual mathematical website with the aim of raising public awareness (RPA) of Mathematics:

www . mathematics-in-europe.eu

It provides information and help for everyone interested in Mathematics. Visitors to the site can find articles on various aspects of the subject including history, philosophy, mathematical professions, and research. The next step is to prepare a database for teachers and to collect helpful information for schoolchildren.

The EMS has requested that those interested in collaborating on this project, to continue to successfully develop and maintain the site, email the chair of their RPA committee:

behrends@math.fu-berlin.de 